\title{
Epileptologists infrequently discuss the risk of intubation with patients with epilepsy in the United States
}

\author{
Andrew J. Solomon ${ }^{1 \wedge}$, Robert Macauley ${ }^{2}$, David Spencer ${ }^{3}$ \\ ${ }^{1}$ Larner College of Medicine at the University of Vermont, Department of Neurological Sciences, Burlington, VT, USA; ${ }^{2}$ Oregon Health \& Science \\ University, Department of Pediatrics, Portland, OR, USA; ${ }^{3}$ Oregon Health \& Science University, Department of Neurology, Portland, OR, USA \\ Contributions: (I) Conception and design: All authors; (II) Administrative support: All authors; (III) Provision of study materials or patients: All \\ authors; (IV) Collection and assembly of data: AJ Solomon; (V) Data analysis and interpretation: All authors; (VI) Manuscript writing: All authors; (VII) \\ Final approval of manuscript: All authors. \\ Correspondence to: Andrew J. Solomon. Larner College of Medicine at the University of Vermont, 1 South Prospect St. Arnold 2, Burlington Vermont, \\ 05401, USA. Email: andrew.solomon@uvm.edu.
}

\begin{abstract}
Background: The aim of this study was to assess how frequently epileptologists discuss advance directives regarding intubation and mechanical ventilation with patients with epilepsy. A secondary aim was to understand the attitudes of neurologists toward discussion and implementation of such advance directives in epilepsy care.
\end{abstract}

Methods: An online study survey was developed and distributed by email invitation to 210 neurologists at academic epilepsy and neurophysiology programs in the United States in December 2018.

Results: Seventy-seven neurologists, 95\% with a clinical practice focus of epilepsy in adults, participated in the study (37\% response rate). Three percent reported discussion of risk of intubation with "every" or a "majority" of patients newly diagnosed with epilepsy. Seventy-seven percent indicated a neurologist was the "most appropriate provider to have discussions concerning mechanical ventilation with patients with epilepsy." Twenty-five percent "strongly agreed" that "every patient with epilepsy should have an advance directive specifying their preferences concerning mechanical ventilation in the setting of treatment for seizures." A majority favored overriding a hypothetical patient's advance directive specifying no intubation in the context of airway compromise as a consequence of status epilepticus and its treatment.

Conclusions: Epileptologists infrequently discuss the risk of intubation and mechanical ventilation with patients with epilepsy. Many felt that such discussions are unnecessary with most patients, but also best led by a neurologist. Neurologists with expertise in epilepsy may favor overriding advance directives in the setting of status epilepticus. Further data is needed surrounding discussion and implementation of advance care planning in patients with epilepsy.

Keywords: Epilepsy; status epilepticus; intubation; advance directives; advance care planning; seizures

Submitted Sep 12, 2020. Accepted for publication Dec 31, 2020.

doi: $10.21037 /$ apm-20-1831

View this article at: http://dx.doi.org/10.21037/apm-20-1831

\section{Introduction}

The annual incidence of status epilepticus is estimated at $10-41$ per 100,000 population (1-3) with an estimated
20,000-30,000 new cases annually in the United States in patients with a known diagnosis of epilepsy (1). Respiratory compromise and subsequent need for mechanical ventilation is a known risk associated with prolonged seizures (1).

\footnotetext{
$\wedge$ ORCID: 0000-0003-1602-1554.
} 
Depending on the cause of status epilepticus, respiratory compromise may often be reversible. Status epilepticus is associated with a mortality of approximately $20 \%(1,2)$, with the most important determinant of survival being its underlying cause. A pre-existing diagnosis of epilepsy and low anti-epileptic drug levels are the most common causes of status epilepticus, and are often associated with a relatively low mortality (1).

A new diagnosis of epilepsy is typically accompanied by counseling by the treating neurologist regarding a number of situations where the occurrence of a seizure may pose further risk of serious injury or even death $(4,5)$. However little is known regarding how often the risk of intubation and mechanical ventilation associated with prolonged seizures is discussed with patients with epilepsy, and whether this situation is addressed in their advance directives.

Older patients are more likely to suffer from epilepsyand experience status epilepticus (2) - as well as have completed an advance directive regarding mechanical ventilation and resuscitation (6), often following a discussion with their primary care physician. For elderly patients with epilepsy, there is also little data concerning whether such discussions take into account the potential for intubation and mechanical ventilation that may be associated with seizures. Furthermore, how the results of advance care planning in such patients-which may include a clinician-signed "do not intubate" order in addition to the patient's advance directive-may be interpreted and acted upon by neurologists in the context of status epilepticus is also unknown.

The aim of this study was to assess how frequently epileptologists discuss advance directives regarding intubation and mechanical ventilation with patients with epilepsy. A secondary aim was to understand the attitudes of neurologists toward discussion and implementation of such advance directives in epilepsy care. We hypothesized that neurologists rarely discuss the risk of respiratory compromise and intubation with mechanical ventilation with patients with epilepsy, and given the likelihood of reversibility of that compromise in the context of status epilepticus, might consider overriding a patient's advance refusal of intubation. We present the following article in accordance with the SURGE reporting checklist (available at http://dx.doi.org/10.21037/apm-20-1831).

\section{Methods}

An online survey instrument was designed by author consensus with the aid of surveymonkey.com (https://
cdn.amegroups.cn/static/public/APM-20-183-1.pdf). The study and survey instrument were approved by the Institutional Review Board at the University of Vermont (FWA00000723, IRB00000485). Informed consent was not required under exemption category 2 . The study was conducted in accordance with the Declaration of Helsinki (as revised in 2013). Responses were anonymous, but an IP address was collected to prevent completion of the survey more than once. Demographic questions were placed at the end of the survey to prioritize questions pertaining to the aims of the study in case participants did not complete the entire survey. Neurologists were identified through public AGCME neurophysiology and epilepsy fellowship databases and also by colleagues at these institutions. A link to the survey instrument with an invitation from study authors was distributed by email invitation to 210 neurologists for adult patients at academic epilepsy and clinical neurophysiology programs in December 2018, and a reminder about the study was sent one week later. The survey was available for completion online for two weeks. There was no incentive offered for completion of the survey.

\section{Statistical analysis}

Descriptive statistics were used to analyze the data.

\section{Results}

\section{Demographics}

Seventy-seven neurologists practicing in the United States participated in the study. The response rate was $37 \%$ (77/210), however not all participants completed the entire survey - this is reflected in the denominator of responses to each question. Ninety-five percent (73/77) of participants reported a clinical practice focus in epilepsy and $96 \%$ (64/67) had completed fellowship training in epilepsy and/ or neurophysiology with a mean duration since completion of residency training of 14.2 years. Seventy percent (47/67) reported greater than $50 \%$ of their FTE was devoted to direct patient care, and 94\% (63/67) reported greater than $50 \%$ of their clinical FTE was devoted to patients with epilepsy. Ninety-four percent (63/67) practiced in an academic setting. Participants cumulatively reported the practice of neurology in 20 different states in the United States. Table 1 presents the full demographic profile of participants. 
Table 1 Participant demographic information

\begin{tabular}{|c|c|}
\hline Demographic characteristic & Response \\
\hline Completion of fellowship & $\begin{array}{l}\text { Epilepsy: 18/67 (27\%); clinical neurophysiology: 13/67 (19\%); epilepsy and clinical } \\
\text { neurophysiology: 33/67 (49\%); no fellowship: } 1 / 67 \text { (1\%); other: 2/67 (3\%) }\end{array}$ \\
\hline Years since completion of residency training & Mean: 14.2; median: 14 \\
\hline Clinical effort devoted to patients with epilepsy & $\begin{array}{l}25 \% \text { or less: } 1 / 67(1 \%) ; 26-50 \%: 3 / 67(4 \%) ; 51-75 \%: 12 / 67 \text { (18\%); } 76 \% \text { or greater: } \\
51 / 67(76 \%)\end{array}$ \\
\hline Practice setting & Academic: 63/67 (94\%); other: 4/67 (6\%) \\
\hline Practice region & $\begin{array}{l}\text { Northeast: 26/68 (38\%); Southeast: 7/68 (10\%); Midwest: 12/68 (18\%); Southwest: } \\
\text { 5/68 (7\%); West: 18/68 (26\%) }\end{array}$ \\
\hline
\end{tabular}

\section{Frequency of discussion of intubation with mechanical ventilation in patients with epilepsy}

The full study survey instrument is available on https:// cdn.amegroups.cn/static/public/APM-20-183-1.pdf. Participants were first presented with a list of thirteen risks and behaviors that may require counseling in association with seizures and were asked how often they discussed each item with a newly diagnosed patient with epilepsy. The list was randomly ordered for each participant. Three percent (2/69) of participants reported discussing intubation with either "every patient" or a "majority" of patients with a new diagnosis of epilepsy. Forty-two percent (29/69) reported discussing status epilepticus with either "every patient", or a "majority" of such patients. Fifty-one percent (35/69) reported discussing sudden death with either "every patient" or a "majority" of newly diagnosed patients. Ninety-nine percent (68/69) reported discussing driving a vehicle with either "every patient" or a "majority" of newly diagnosed patients. Table 2 presents the complete list of risks and behaviors as well as responses from all participants.

Participants were then asked to estimate the percentage of all of their patients with epilepsy with whom they have ever discussed the risk of respiratory depression requiring mechanical ventilation associated with treatment for prolonged seizures. Averaged over 68 participants, the response was $14 \%$, with a median of $5 \%$.

\section{Attitudes toward advance care planning for intubation with mechanical ventilation in patients with epilepsy}

Participants were asked questions that assessed their attitudes toward advance care planning for intubation and mechanical ventilation with patients with epilepsy. Full results of responses are in Table 3. Seventy-seven percent (53/69) responded that a neurologist was the most appropriate provider to initiate discussions concerning mechanical ventilation with patients with epilepsy. Twenty-five percent $(17 / 69)$ responded that they "strongly agree" and $28 \%$ $(19 / 69)$ that they "agree somewhat" with the assertion that "every patient with epilepsy should have an advance directive specifying their preferences concerning mechanical ventilation in the setting of treatment for seizures."

A hypothetical clinical case was then presented to participants (see https://cdn.amegroups.cn/static/public/ APM-20-183-1.pdf for full description). This case described a 73-year-old patient with a known history of epilepsy and of myocardial infarction and cardiovascular disease, who had been unable to take her antiepileptic medication due to vomiting as a result of a viral illness and who presented for care after two generalized tonic-clonic seizures with incomplete recovery and respiratory compromise presumed secondary to treatment with intravenous lorazepam. A Portable Order for Life Sustaining Treatment (POLST) form specifying do not resuscitate/do not intubate (DNR/DNI) without additional detail is identified for the patient, and family is unavailable. Thirty-one percent (21/67) of participants indicated it was "extremely likely" and $37 \%(25 / 67)$ "likely" that they would recommend intubation of this patient.

Following the case, 37\% (25/67) of participants responded that they "strongly agree" and 19\% (13/67) that they "agree somewhat" with the statement "a documented Do Not Intubate order should only be honored if the cause of respiratory arrest is likely irreversible". 
Table 2 Frequency of discussion of risks and behaviors in a patient with a new diagnosis of epilepsy

\begin{tabular}{|c|c|c|c|c|c|}
\hline Risks and behaviors & Every patient [\%] & Majority of patients [\%] & Some patients [\%] & Few patients [\%] & No patients [\%] \\
\hline Driving a vehicle & $60 / 69$ [87] & $8 / 69[12]$ & 0/69 [0] & $0 / 69[0]$ & $1 / 69[1]$ \\
\hline $\begin{array}{l}\text { Working or recreating at } \\
\text { heights }\end{array}$ & $46 / 69[67]$ & $15 / 69$ [22] & $7 / 69[10]$ & 0/69 [0] & $1 / 69$ [1] \\
\hline Operating heavy machinery & $37 / 69[54]$ & 20/69 [29] & $11 / 69[16]$ & $1 / 69[1]$ & 0/69 [0] \\
\hline $\begin{array}{l}\text { Bathing, swimming, or } \\
\text { scuba diving }\end{array}$ & $49 / 69[71]$ & $16 / 69$ [23] & $4 / 69[6]$ & 0/69 [0] & 0/69 [0] \\
\hline Alcohol consumption & $31 / 69[45]$ & $26 / 69$ [38] & $8 / 69[12]$ & 3/69 [4] & $1 / 69[1]$ \\
\hline Operating an aircraft & $9 / 69[13]$ & $2 / 69$ [3] & $4 / 69[6]$ & $38 / 69[55]$ & $16 / 69$ [24] \\
\hline Sleep deprivation & $31 / 69[45]$ & $28 / 69[41]$ & $7 / 69[10]$ & 2/69 [3] & $1 / 69[1]$ \\
\hline Intubation & 0/69 [0] & $2 / 69[3]$ & $17 / 69$ [25] & $24 / 69$ [35] & $26 / 69$ [38] \\
\hline Sudden death & $11 / 69[16]$ & $24 / 69$ [35] & $19 / 69$ [28] & $13 / 69[19]$ & 2/69 [3] \\
\hline Cognitive impairment & $8 / 69$ [12] & $19 / 69$ [28] & $27 / 69$ [39] & $11 / 69[16]$ & $4 / 69[6]$ \\
\hline Fractures & $7 / 69[10]$ & $13 / 69[19]$ & 23/69 [33] & $17 / 69[25]$ & 9/69 [13] \\
\hline Psychosis & $1 / 69$ [1] & $4 / 69[6]$ & 22/69 [32] & $30 / 69$ [43] & $12 / 69[17]$ \\
\hline Status epilepticus & $7 / 69[10]$ & $22 / 69$ [32] & $25 / 69[36]$ & $11 / 69[16]$ & $4 / 69[6]$ \\
\hline
\end{tabular}

Table 3 Attitudes toward advance directives for intubation with mechanical ventilation

\begin{tabular}{ll}
\hline Question surveyed & Responses \\
\hline $\begin{array}{l}\text { Most appropriate provider to have discussions concerning } \\
\text { mechanical ventilation with patients with epilepsy }\end{array}$ & PCP: 3/69 (4\%); neurologist: 53/69 (77\%); other: 13/69 (19\%) \\
$\begin{array}{l}\text { "Every patient with epilepsy should have an advance directive } \\
\text { specifying their preferences concerning mechanical ventilation in }\end{array}$ & $\begin{array}{l}\text { Strongly agree: 17/69 (25\%); agree somewhat: 19/69 (28\%); neutral } \\
\text { or neither agree or disagree: 10/69 (14\%); disagree: 19/69 (28\%); } \\
\text { strongly disagree: 4/69 (6\%) }\end{array}$ \\
$\begin{array}{ll}\text { Hypothetical case of a patient with status epilepticus and DNR/DNI } \\
\text { order-likelihood of recommending intubation }\end{array}$ & $\begin{array}{l}\text { Extremely likely: 21/67 (31\%); likely: 25/67 (37\%); neutral/not sure: } \\
\text { "A docu (13\%); not likely: 7/67 (10\%); extremely unlikely: 5/67 (7\%) }\end{array}$ \\
"A documented Do Not Intubate order should only be honored if & $\begin{array}{l}\text { Strongly agree: 25/67 (37\%); agree somewhat: 13/67 (19\%); neither } \\
\text { agree nor disagree: 8/67 (12\%); disagree: 17/67 (25\%); strongly } \\
\text { dhe cause of respiratory arrest is likely irreversible" }\end{array}$ \\
\hline
\end{tabular}

PCP, primary care provider; DNR, do not resuscitate; DNI, do not intubate.

\section{Discussion}

To our knowledge, the issue of advance care planning in epilepsy has received relatively little attention. This study suggests that academic epilepsy specialists infrequently discuss the risk of intubation and mechanical ventilation with patients with epilepsy. These neurologists indicated that they rarely initiate such discussions in routine counseling with patients in whom they had made a new diagnosis of epilepsy, or during subsequent clinical encounters. This is particularly surprising given the relatively high prevalence of status epilepticus in patients with epilepsy (1). By comparison, an estimated $30 \%$ of adults in the United States without a known medical problem have completed a treatment directive (sometimes referred to as a "living will"), healthcare power of attorney, or both (6). Interestingly by contrast, the epileptologists participating in this study reported that they frequently discussed status epilepticus $(42 \%)$ and sudden unexpected death in epilepsy (51\%) with patients with a new diagnosis of epilepsy. The initiation of 
counseling regarding sudden unexpected death in epilepsy and status epilepticus might provide an opportune time to elicit, and document, preferences pertaining to intubation and mechanical ventilation in patients with epilepsy.

Although a majority of participants indicated that neurologists, rather than primary care doctors, were the best-suited providers to initiate discussions concerning advance directives with patients with epilepsy, only a quarter of participants strongly endorsed the importance of such discussions in all patients with epilepsy. More than a third disagreed that all patients with epilepsy should receive such counseling. Further data is needed to understand the reasons for this. Despite the fact that advance directives empower patients to exercise their autonomy at a time of incapacity - and over $70 \%$ of elderly Americans will lose decision-making capacity at some point (7)—as noted, only about one-third of Americans actually complete one (6). Ideally advance care planning would take place in the context of a longitudinal clinical relationships, but primary care physicians may be reluctant to engage in this conversation with patients with neurological illness if the physician does not feel sufficiently informed about the relative risks and benefits of certain interventions. Conversely, neurologists may feel ill-equipped to engage in such conversations (8), which often encompass issues outside of their specialty. The result, unfortunately, is lost opportunities for advance care planning. Although numerous barriers to implementing advance directive planning are widely acknowledged in primary care (9), it's possible to speculate that disease-specific considerations may also influence the frequency of such discussions in the care of patients with epilepsy. Epileptologists may be of the opinion that advance directive discussion is best reserved for patients with severe or refractory epilepsy who might be at higher risk for intubation in the future, or that discussion is generally unnecessary since intubation and mechanical ventilation associated with seizures is frequently reversible. However this approach is likely inadequate, as predicting the future severity of epilepsy, particularly at time of diagnosis, is challenging $(10,11)$, and status epilepticus is associated with mortality (12).

Consideration of advance directives in older patients with epilepsy deserves special attention. Such patients are more likely to face intubation for seizures due to both higher risk of status epilepticus (2), as well as increased sensitivity to central nervous system directed medications often employed for treatment. Discussion of advance directives in such patients can be challenging and nuanced. Older patients may have a number of comorbid and potentially life-limiting conditions in addition to epilepsy, and a DNI order as part of a POLST may be in place as a result of a discussion with a primary care doctor centered on such conditions without adequate consideration of concurrent epilepsy. Some causes of epilepsy in older adults, such as metastatic neoplasms and progressive neurodegenerative disease, may ultimately be life limiting, while other causes may not. Without a neurologist's involvement to ensure decisions surrounding advance directives take into consideration a diagnosis of epilepsy, an approach to treatment at the time of an emergency can be fraught with uncertainty regarding the patient's wishes. Furthermore, data are lacking on recovery from status epilepticus in older adults to help best inform advance directive discussions.

In our hypothetical clinical case, a majority (68\%) of epileptologists indicated they might override a POLST indicating a DNI order for the treatment of status epilepticus. Overriding advance directives, particularly when specific life-prolonging treatment such as intubation with mechanical ventilation is explicitly declined, is ethically problematic (13). In older patients with epilepsy requiring intubation where the cause of seizures is perceived to be reversible, but a DNI is in place without further specific information, it may not be immediately obvious how to interpret such a directive. In such situations, additional context is critical. Some patients might-based on personal experience or lack of complete information-believe that intubation invariably leads to prolonged mechanical ventilation and a low likelihood of a favorable outcome. If that is what the patient was attempting to avoid, then short-term mechanical ventilation to allow for the return of spontaneous respiration would be appropriate. On the other hand, if the patient's current quality of life was not acceptable to the patient-leading them to reject any burdensome intervention, of whatever duration or outcome-then the DNI order should be honored, even in the context of a remediable condition. Of the two-thirds of respondents who "might override" a DNI order, it isn't clear how many would do so because of uncertainty about whether intubation might actually be consistent with the patient's wishes, and how many felt a professional obligation to treat the side effect of an intervention, irrespective of the patient's goals and values.

This study has limitations. The survey was not previously validated. The response rate was $37 \%$, which although acceptable for a physician survey, may have introduced bias. The majority of participants were academic neurologists 
with both expertise and a practice focus in epilepsy. Verification of training and practice characteristics was by self-report. Community neurologists who often care for patients with epilepsy were not surveyed and how their approach to advance directives concerning intubation and mechanical ventilation in patients with epilepsy may differ is unknown. To what extent responses, especially regarding a hypothetical clinical case, mirror actual clinical care and decision-making in practice is also unknown. The study was restricted to epileptologists who care for adult patients. Children can and do have advance directives, and some children with epilepsy are at high risk for intubation. Advance care planning for pediatric epilepsy would likely involve parents or caregivers in addition to patients, but data for such conversations is also lacking in this population. Some pediatric as well as adult patients with severe epilepsy may be unable to express their wishes in regard to advance care planning, and such discussions would necessitate involving family and health care decision-makers for such patients. This population was not specifically addressed by the current study is an important area for further research.

\section{Conclusions}

Our study raises a number of questions surrounding advance directives in patients with epilepsy. Should advance directives pertaining to intubation and mechanical ventilation be discussed with all patients with epilepsy? Is such discussion best restricted to a subset of patients? Should this effort be led by neurologists? Is there a need for an epilepsy specific advance directive with a clause about intubation as a result of status epilepticus (in distinction from other conditions)? Should completion of advance directives or an advance directive discussion be incorporated into quality metrics for epilepsy care? How can successful coordination of advance directive conversations, documentation, and implementation be ensured between neurologists and primary care providers who share the care of patients who suffer from both epilepsy and non-neurological medical problems? How should advance directives that include DNI be interpreted in presentations of status epilepticus? To our knowledge, there is little literature focused on these questions in epilepsy. Further data concerning patient and provider attitudes toward discussion and implementation of advance care planning in patients with epilepsy is needed to guide best care decisions.

\section{Acknowledgments}

Funding: None.

\section{Footnote}

Reporting Checklist: The authors have completed the SURGE reporting checklist. Available at http://dx.doi. org/10.21037/apm-20-1831

Data Sharing Statement: Available at http://dx.doi. org/10.21037/apm-20-1831

Conflicts of Interest: All authors have completed the ICMJE uniform disclosure form (available at http://dx.doi. org/10.21037/apm-20-1831). AJS has served as a paid consultant for Alexion, Biogen, Celgene, and EMD Serono, and Greenwich Biosciences, has received research support from Biogen, and is engaged in contracted research with Actelion, Genentech, Novartis and Biogen, outside the submitted work. The other authors have no conflicts of interest to declare.

Ethical Statement: The authors are accountable for all aspects of the work in ensuring that questions related to the accuracy or integrity of any part of the work are appropriately investigated and resolved. The study and survey instrument were approved by the Institutional Review Board at the University of Vermont (FWA00000723, IRB00000485). Informed consent was not required under exemption category 2 . The study was conducted in accordance with the Declaration of Helsinki (as revised in 2013).

Open Access Statement: This is an Open Access article distributed in accordance with the Creative Commons Attribution-NonCommercial-NoDerivs 4.0 International License (CC BY-NC-ND 4.0), which permits the noncommercial replication and distribution of the article with the strict proviso that no changes or edits are made and the original work is properly cited (including links to both the formal publication through the relevant DOI and the license). See: https://creativecommons.org/licenses/by-nc-nd/4.0/.

\section{References}

1. Betjemann JP, Lowenstein DH. Status epilepticus in adults. Lancet Neurol 2015;14:615-24.

2. Dham BS, Hunter K, Rincon F. The epidemiology of 
status epilepticus in the United States. Neurocrit Care 2014;20:476-83.

3. Leitinger M, Trinka E, Giovannini G, et al. Epidemiology of status epilepticus in adults: A population-based study on incidence, causes, and outcomes. Epilepsia 2019;60:53-62.

4. Noe K. Counseling and Management of the Risks of Living With Epilepsy Continuum (Minneap Minn) 2019;25:477-91.

5. Gavvala JR, Schuele SU. New-Onset Seizure in Adults and Adolescents: A Review. JAMA 2016;316:2657-68.

6. Yadav KN, Gabler NB, Cooney E, et al. Approximately One In Three US Adults Completes Any Type Of Advance Directive For End-Of-Life Care. Health Aff (Millwood) 2017;36:1244-51.

7. Silveira MJ, Kim SY, Langa KM. Advance directives and outcomes of surrogate decision making before death. $\mathrm{N}$

Cite this article as: Solomon AJ, Macauley R, Spencer D. Epileptologists infrequently discuss the risk of intubation with patients with epilepsy in the United States. Ann Palliat Med 2021;10(4):3626-3632. doi: 10.21037/apm-20-1831
Engl J Med 2010;362:1211-8.

8. Borasio GD. The role of palliative care in patients with neurological diseases. Nat Rev Neurol 2013;9:292-5.

9. Spoelhof GD, Elliott B. Implementing advance directives in office practice. Am Fam Physician 2012;85:461-6.

10. Kwan P, Brodie MJ. Early identification of refractory epilepsy. N Engl J Med 2000;342:314-9.

11. Sillanpää M, Schmidt D. Long-term outcome of medically treated epilepsy. Seizure 2017;44:211-6.

12. Nelson SE, Varelas PN. Status Epilepticus, Refractory Status Epilepticus, and Super-refractory Status Epilepticus. Continuum (Minneap Minn) 2018;24:1683-707.

13. Banja J, Sumler M. Overriding advance directives: A 20year legal and ethical overview. J Healthc Risk Manag 2019;39:11-8. 